\title{
A Proposal for an African Investment Guarantee Agency (AIGA) and the Valuation of Associated Instruments
}

\author{
Joseph Atta-Mensah \\ Macroeconomics and Governance Division, United Nations Economic Commission for Africa, Addis Ababa, Ethiopia \\ Email: atta-mensahj@un.org
}

How to cite this paper: Atta-Mensah, J. (2019) A Proposal for an African Investment Guarantee Agency (AIGA) and the Valuation of Associated Instruments. Theoretical Economics Letters, 9, 2436-2446. https://doi.org/10.4236/tel.2019.97154

Received: August 12, 2019

Accepted: September 27, 2019

Published: September 30, 2019

Copyright (อ 2019 by author(s) and Scientific Research Publishing Inc. This work is licensed under the Creative Commons Attribution International License (CC BY 4.0).

http://creativecommons.org/licenses/by/4.0/

\begin{abstract}
The paper calls for the creation of an African Investment Guarantee Agency (AIGA) to support and strengthen the financing of development projects, including infrastructure projects. The main objective of AIGA would be to provide noncommercial investment guarantees to African and non-African investors, private or public who are desirous of investing in Africa but do not have the appetite for the above non-commercial risks. Using option-pricing techniques, the paper derives the cost of AIGA's guarantees and the associated implied risk premium. Using infrastructure-linked bonds as an example, the paper indicates that the risk premium embedded in an infrastructure-indexed bond contract is seen as a function of the ratio of the cost of the infrastructure-indexed bond guarantee and the present value of the promised payment.
\end{abstract}

\section{Keywords}

Indexed-Linked Bonds, Investment Guarantee and Risk Premium

\section{Introduction}

Traditionally, Africa has been relying on donor partners, such as the World Bank, European Commission and others, to finance most of its developmental agenda. The African Development Bank has also contributed significantly in financing some of the infrastructure programmes of African countries. Most of the financing arrangements have been partnership between the governments (on behalf of its public sector) and the aforementioned institutions with the private sectors left to raise its own capital. With exception of Johannesburg Stock Exchange, in South Africa, and Alexandra Stock Exchange in Egypt, most of the 
capital markets are not well developed. The purpose of this note is to provide a framework for the strengthening of the financial sector of the continent, with a particular focus on a suggestion for the creation of an African Guarantee Investment Agency (AIGA).

Section 2 of this note provides a framework for the creation of AIGA. Section 3 focuses on the pricing of the guarantee investments instruments. Recommendations and conclusions are contained in Section 4.

\section{Africa's Infrastructure Spending Needs ${ }^{1}$}

Addressing the infrastructure deficit in Africa would require massive investments for the operation and maintenance of existing infrastructure. Investments are needed to: develop an additional 7000 megawatts a year of new power generation capacity; enable regional power trade by laying 22,000 megawatts of cross-border transmission lines; complete the intraregional fibre-optic backbone network and continental submarine cable loop; interconnect capitals, ports, border crossings, and secondary cities with a good quality road network; provide all-season road access to Africa's high-value agricultural land; more than double Africa's irrigated area; provide clean and portable water and sanitation so that the continent will meet the Sustainable Development Goals (SDGs); raise household electrification rates by 10 percentage points; as well as provide global systems mobile voice signal and public access broadband to 100 percent of the population.

The World Bank studies, [1], estimate that the price tag for developing Africa's infrastructure is around US\$93 billion a year (about 15 percent of Africa's GDP). Two-thirds of this amount is for capital expenditure, and the remaining one-third for operation and maintenance requirements (see Table 1).

As shown in Table 1 about 40 percent of the total spending needs are associated with power. After power, water supply and sanitation and then transport are the most significant items.

The good news is that a large share of Africa's infrastructure needs is being financed through domestic resources. Out of the USD $\$ 45.3$ billion current annual spending on Africa's infrastructure, about UD $\$ 29.8$ billion is financed by African taxpayers and infrastructure users, US $\$ 9.4$ billion by the private sector and the rest from external sources (see Table 2). This assessment is contrary to current perceptions that most of current infrastructure financing is from external sources. It is also important to note that Overseas Development Assistance (ODA) and Non-OECD financiers (China, India, Arab States and others) contributed US $\$ 3.6$ billion and USD $\$ 2.5$ billion respectively, to the current spending on Africa's infrastructure.

Water, energy, and transport infrastructures are mainly financed through Africa's public sector. Public investment is largely tax financed and executed through central government budgets, whereas the operating and maintenance expenditure is largely financed from user charges and executed through state-owned enterprises.

${ }^{1}$ This section is based on [1]. 
Table 1. Infrastructure spending needs for Africa.

\begin{tabular}{cccc}
\hline Infrastructure Sector & Capital Expenditure & Operation and Maintenance Total Spending \\
\hline ICT & 7.0 & 2.0 & 9.0 \\
Irrigation & 2.9 & 0.6 & 3.4 \\
Power & 26.7 & 14.1 & 40.8 \\
Transport & 8.8 & 9.4 & 18.2 \\
Water Supply and Sanitation & 14.9 & 7.0 & 21.9 \\
Total & 60.4 & 33.0 & 93.3 \\
\hline
\end{tabular}

Source: Africa Infrastructure Country Diagnostic 2010.

Table 2. Infrastructure spending on Africa's infrastructure needs (in billion of USD).

\begin{tabular}{cccccccc}
\hline & $\begin{array}{c}\text { Operation and } \\
\text { Maintenance }\end{array}$ & \multicolumn{7}{c}{ Capital Expenditure } \\
\hline $\begin{array}{c}\text { Infrastructure } \\
\text { Sector }\end{array}$ & Public Sector & Public Sector & ODA & $\begin{array}{c}\text { Non-OECD } \\
\text { Financiers }\end{array}$ & $\begin{array}{c}\text { Private } \\
\text { Sector }\end{array}$ & Total & $\begin{array}{c}\text { Total } \\
\text { Spending }\end{array}$ \\
\hline ICT & 2.0 & 1.3 & 0.0 & 0.0 & 5.7 & 7.0 & 9.0 \\
Power & 7.0 & 2.4 & 0.7 & 1.1 & 0.5 & 4.6 & 11.6 \\
$\begin{array}{c}\text { Transport } \\
\text { Water Supply }\end{array}$ & 7.8 & 4.5 & 1.8 & 1.1 & 1.1 & 8.4 & 16.2 \\
and Sanitation & 3.1 & 1.1 & 1.2 & 0.2 & 2.1 & 4.6 & 7.6 \\
Irrigation & 0.6 & 0.3 & - & - & - & 0.3 & 0.9 \\
Total & 20.4 & 9.4 & 3.6 & 2.5 & 9.4 & 24.9 & 45.3 \\
\hline
\end{tabular}

Source: Africa Infrastructure Country Diagnostic 2010.

In terms of capital expenditure, the private sector participation is about the same as those from the public sector. However most of the expenditures of the private sector are targeted towards the development of ICTs. Also it is observed that private participation in infrastructure, and non-OECD financiers together exceed domestically financed public investment. ODA commitments are targeted towards water, energy and transport sectors. The Non-OECD resources are observed to be targeted more to energy and rail, particularly for resource-rich African countries.

Africa's annual financing gap for its infrastructure development is about US $\$ 48$ billion if the current expenditure remains at US $\$ 45.3$ billion annually. The projected annual financing needs to strengthen and develop Africa's infrastructure at world standards is about US\$93.3 (see Table 3). It must be noted that given the recent spikes in oil prices and escalations in the unit costs of infrastructure these estimates are at the lower boundary.

It is also important to note that the current delivery of Africa's infrastructure is fraught with inefficiencies. These inefficiencies vary from country to country. It is observed that some African countries are spending more resources than needed in some sectors of infrastructure. This excess expenditure is estimated by 
Table 3. Infrastructure financing gap for Africa (in billions of USD).

\begin{tabular}{cccc}
\hline Infrastructure Sector & Total Spending Needs & Total Current Expenditure & Financing Gap \\
\hline ICT & 9.0 & 9.0 & 0.0 \\
Irrigation & 3.4 & 0.9 & 2.5 \\
Power & 40.8 & 11.6 & 29.2 \\
Transport & 18.2 & 16.2 & 2.0 \\
Water Supply and Sanitation & 21.9 & 7.6 & 14.3 \\
Total & 93.3 & 45.3 & 48.0 \\
\hline
\end{tabular}

Source: Africa Infrastructure Country Diagnostic 2010.

the World Bank to be around US $\$ 3.3$ billion annually. The largest share of this excess expenditure relates to public spending on ICT infrastructure that the private sector could provide, particularly in middle-income countries.

Another source of inefficiency lies in the execution of infrastructure budget. It is estimated that African countries are executing only about two-thirds of the budget allocated to public investment in infrastructure. This means that public investment could, in theory, increase by 30 percent without any increase in spending, simply by addressing the institutional bottlenecks that inhibit capital budget execution. Some of the measures needed to address this inefficiency include better planning of investment projects, earlier completion of feasibility studies, more efficient procurement processes, and a move to medium-term multiyear budgeting. Addressing this inefficiency is estimated to save African countries an additional $\$ 1.9$ billion a year in public investment in infrastructure.

Lack of proper maintenance and rehabilitation of Africa's infrastructure assets introduces inefficiency in the delivery of the service. It is estimated that on average, about 30 percent of Africa's infrastructure needs rehabilitation. The backlogs in rehabilitation stem from under funding of maintenance, a major waste given that the cost of rehabilitating infrastructure is several times higher than the cumulative cost of sound preventive maintenance. It is estimated that about \$2.4 billion of capital spending on rehabilitation of Africa's roads could have been avoided with sound preventive maintenance.

Africa's power and water utilities also face operational difficulties. These are associated with distribution losses, under-collection of revenues, and overstaffing. It is observed that state-owned utilities companies in many African countries collect only $70 \%$ to $90 \%$ of billed revenues due to rent-seeking activities. Overall, the revenues lost through these inefficiencies can be very high. It is estimated that energy sector loses amount to about US $\$ 3.4$ billion annually and that for the water sector to about US\$1 billion a year.

Under-pricing of Africa's infrastructure services also results in substantial losses. As noted earlier African infrastructure charges are high by international standards. However, because of inefficiencies infrastructure costs are also very high. Hence the relatively high tariffs fail to cover the operating costs of infrastructure services. It is estimated that uncollected revenues due to under-pricing 
of power and water amount to as much as $\$ 4$ billion a year.

The World Bank estimates that if all these potential infrastructure inefficiencies are addressed, Africa could save about US\$17 billion. Hence if all these efficiency gains are fully realized, Africa's infrastructure funding gap would be about $\$ 31$ billion a year.

\section{Suggested Framework for AIGA}

The financing of Africa's development projects could be strengthened through the establishment of an African Investment Guarantee Agency (AIGA). AIGA's functions could be similar to the World Bank's MIGA but would cater to only investments in Africa, providing guarantees to Africa's fragile private sector.

The World Bank's MIGA, which was created in 1988, aims at promoting cross-border investments in developing countries by providing guarantees (political risk insurance and credit enhancement) to investors and lenders. The risks covered by MIGA include currency transfers restrictions, expropriation and war and civil disturbance. MIGA guarantees therefore protect investments against non-commercial risks and can help investors obtain access to funding sources with improved financial terms and conditions. The membership of MIGA, which is opened to all the member countries of the World Bank, currently has 156 developing countries and 25 industrialized countries. In addition to its investment guarantees, MIGA also offers technical assistance to its members in strategies that contribute to the promotion of FDIs. Its legal wing could be used is settling disputes and disagreements between investors and governments.

AIGA could have a mission of promoting investments in Africa, particularly in the area of infrastructure development. Why AIGA when there is MIGA? Despite its good work in facilitating and promoting FDIs to developing countries, MIGAs focus is very broad and therefore the assistance to Africa is smaller than what is expected. AIGA, if properly created, would focus only on Africa as its members would be made up of only of African countries and would be charged with the sole task of assisting private investments on the continent. This agency is also needed because of the difficulties African countries face in attracting productive capital for financing projects, as international investors perceive the countries to be of high risk due to political instability and other non-financial risks that have plagued the continent for some time now. Moreover, if managed well, AIGA has a potential of generating enough profits that could be ploughed back into the continent's economy.

AIGA could be created as a wing of the African Development Bank or as part of the African Investment Bank proposed under the 1991 Abuja Treaty or as a separate entity. This task could be left to the leadership of the African Union (AU).

The main objective of AIGA would be to provide non-commercial investment guarantees to African and non-African investors, private or public, who are desirous of investing in Africa but do not have the appetite for the above non-commercial risks. Like those covered by MIGA, these risks could include an 
investors inability to repatriate funds because of an unstable political environment in a country, war or civil or sectarian conflicts and unlawful nationalization, confiscation and seizure of investment projects by the government of a host country. (The exact definition of risks could be left in the hands of a legal team that would be responsible for carving out the legal text and protocols that would govern the operation of the Agency.)

The structure of AIGA should be such that its membership is opened mainly to African countries. However, a small fraction of ownership could go to other non-African countries. Each member states would contribute to the initial capital needed to operate the agency plus an agreed annual membership fee. The membership of the Agency would have to agree on the currency of operation. A suggestion is that the currency be convertible in international financial markets. Depending on the financial health of the Agency, members could be paid dividends from accrued profits.

The Board of Directors of AIGA could be made up of the Finance Ministers of the African countries who hold membership in the Agency. Representatives of non-African countries who are members could be non-voting members of the board. The Board would be responsible for appointing the President of the Agency. Depending on the structure of the Agency, the Board could appoint a number of vice-presidents. The Board should be empowered to set policies, regulations and rules that would ensure the smooth operation of the Agency. The President is empowered to oversee the day-to-day activity of the Agency.

Under the direction of the Board, the President would approve all guarantee-contracts between the Agency and investors. However, the President must ensure that not all investors receive guarantees. For example, investment that are very risky and have high chance of failure should not be covered so as to reduce "moral hazards" or "adverse selection" bias. In other words, the Agency, led by the President, should strike a balance between ensuring the sound financial health of the Agency and the provision of coverage that would attract productive investment to the continent.

In addition to a number of units that must be created to assist the President in running the Agency, AIGA should have a risk management unit. The risk management unit would be responsible for managing all the risk exposures the Agency faces. The unit must be equipped with modern tools, techniques and the best minds in the field. As part of its assignment, the unit must be able to determine the actuarial fair premiums each applicant must pay in order to receive a guarantee from AIGA. The unit would in turn invest the premiums on behalf of AIGA in both financial and physical assets. It is very important that the President, under the direction of the Board, keeps a careful eye on the risk management unit because it would be the lifeline of the Agency.

\section{The Cost of Guarantee Instruments ${ }^{2}$}

To analyze the cost of a guarantee instrument we will take the example of an in-

${ }^{2}$ This Section is inspired by [2]. 
frastructure project which is being financed through the issuance of bonds linked to the project. Following [3] let us assume that the face value of an infrastructure-indexed bond is $F$ and the market of value of the project is $V$, then the expected value of the infrastructure-indexed bond at the end of the contract is:

$$
\operatorname{Min}[F, V]
$$

It is assumed that embedded in $F$ are all the necessary costs incurred by the bond-holders upon defaulting of the contract. ${ }^{3}$ Further assumptions are: 1) assets are traded in a frictionless or perfect market, where there are no taxes, transactions costs, or short sale restrictions, and all assets are perfectly divisible; 2) trading of assets is done continuously; 3) the value of the project follows a continuous-time diffusion process; and 4) lenders and borrowers have the same information on, and identical beliefs in, the prospects for the project.

Let $V(t)$ be the market value of the project and its stochastic process be of the form:

$$
\frac{\mathrm{d} V}{V}=\left(\alpha_{v}-\frac{\delta}{V}\right) \mathrm{d} t+\sigma_{v} \mathrm{~d} z_{v}
$$

where $\mathrm{d} z_{v}$ is a standard Brownian motion, with mean zero and variance $\mathrm{d} t$. In Equation (2), it is assumed that the project pays out dividends at a constant rate, d. The diffusion part (the second part on the right-hand side) of Equation (2) makes the instantaneous rate of appreciation of the project uncertain. Hence, the expected rate of appreciation of the project is $\left(\alpha_{v}-\frac{\delta}{V}\right)$.

Given that the bond is indexed to the market value of the infrastructure project, the market value of the bond at any given time is $B(V, t)$. Using the Ito's lemma, the drift and the diffusion of the bond could be expressed as:

$$
\mathrm{d} B=B_{v} \mathrm{~d} V+\frac{1}{2} B_{v v}(\mathrm{~d} V)^{2}+B_{t} \mathrm{~d} t
$$

or:

$$
\frac{\mathrm{d} B}{B}=\alpha_{b} \mathrm{~d} t+\sigma_{b} \mathrm{~d} z_{b}
$$

and

$$
\begin{gathered}
\alpha_{b}=\frac{\frac{1}{2} \sigma_{v}^{2} V^{2} B_{v v}+\left(\alpha_{v}-\frac{\delta}{V}\right) V B_{v}+B_{t}+c}{B} \\
\sigma_{b}=\frac{\sigma_{v} V B_{v}}{B}
\end{gathered}
$$

$c$ is the instantaneous coupon rate paid to bond holders.

Standard arbitrage arguments common in the options-pricing literature will show the partial differential equation governing the infrastructure-indexed bond, which pays an instantaneous coupon rate of $c$ is:

${ }^{3}$ These costs may include bankruptcy, legal, and reputation costs. 


$$
\frac{1}{2} \sigma_{v}^{2} V^{2} B_{v v}+(r V-\delta) B_{v}+B_{t}-r B+c=0
$$

Following [2] the present value of the bond under the set of assumptions is:

$$
B(V, \tau)=\frac{c}{r}\left(1-\mathrm{e}^{-r \tau}\right)+F \mathrm{e}^{-r \tau}-P(V, F, \tau)
$$

$P(V, F, t)$ is a European put option on the infrastructure project, $V$, with constant dividend $\delta V$ and an exercise price equal to the principal payment, $F$. The value of the put option is:

$$
P(V, F, \tau)=F \mathrm{e}^{-r \tau} N\left(d_{1}\right)-V \mathrm{e}^{-\delta \tau} N\left(d_{2}\right)
$$

where

$$
\begin{gathered}
d_{1}=\frac{\log \left(\frac{F}{V}\right)+\left((\delta-r)+\frac{1}{2} \sigma_{v}^{2}\right) \tau}{\sigma_{v} \sqrt{\tau}} \\
d_{2}=d_{1}-\sigma_{v} \sqrt{\tau}
\end{gathered}
$$

and $N($.$) is the cumulative normal distribution function.$

Equation (9) indicates that the value of the infrastructure-indexed bond is a function of the value of the project, creating an incentive needed to ensure that the project is carried through.

Now let us consider a case in which there is a third party that guarantees to pay the lender should the borrower default. This contract, between the borrower and the guarantor, would require that the borrower surrender the project to the guarantor in the event of an infrastructure-indexed bond default. Note that the project could be the assets of the borrower or the value of the project being financed with the infrastructure-indexed bond.

Before we provide the pricing formula for the cost of the guarantee, we analyze the pay-offs under various states of the world. On the maturity date of the infrastructure-indexed bond, if the value of the project, $Q$, exceeds the promised payment of the infrastructure-indexed bond, $F$, then the borrower pays the lender, $F$, and keeps $Q-F$. On the other hand, if the value of the project, $Q$, is less than the promised payment of the infrastructure-indexed bond, $F$, the third party pays the lender $F$ and takes a loss of $F$ - $Q$, with the borrower receiving nothing.

The contractual arrangement suggests that, at the maturity date, the lender will receive the promised payment, $F$, regardless of the state of the world. Thus, to the lender the infrastructure indexed bond is riskless. The net receipt for the borrower is $\max (0, Q-F)$, with or without a guarantee. The net receipt to the guarantor is $\max (0, Q-F)$, which is non-positive. As a result of the guarantee, the borrower receives an additional cash inflow of $-\min (0, Q-F)$, or $\max (0, F-Q)$. Hence, if $G(\tau)$ is the value of the guarantee to the borrower, then

$$
G(0)=\max (0, F-Q),
$$


which is equivalent to a put option. Equation (10) gives the exact formula for evaluating the option. Hence

$$
P(Q, F, \tau)=F \mathrm{e}^{-r \tau} N\left(d_{1}\right)-Q \mathrm{e}^{-\delta \tau} N\left(d_{2}\right)
$$

where

$$
\begin{gathered}
d_{1}=\frac{\log \left(\frac{F}{Q}\right)+\left((\delta-r)+\frac{1}{2} \sigma_{q}^{2}\right) \tau}{\sigma_{q} \sqrt{\tau}} \\
d_{2}=d_{1}-\sigma_{q} \sqrt{\tau}
\end{gathered}
$$

and $N($.$) is the cumulative normal distribution function { }^{4}$.

Equation (11) The cost of the infrastructure-indexed bond guarantee is therefore equivalent to an European put option, the underlying asset of which is $Q$ and the exercise price $F$.

\section{Risk Premium}

Let us derive an expression for the risk premium embedded in the infrastructure-indexed bond contract. To a lender, an infrastructure-indexed bond that is guaranteed by the borrower is riskless. The difference between the yield on an infrastructure-indexed bond that is not guaranteed and one that is guaranteed is a measure of the risk premium.

Now let $y(\tau)$ be the implied yield of the debt, $F$, when there is no guarantee. This implies that the present value of the debt is $F \exp (-y(\tau) \tau)$. With the infrastructure-indexed bond guaranteed, the lender is assured $F$, which is either paid by the borrower or the guarantor. The present value of the guaranteed infrastructure-indexed bond is therefore $F \exp (-r(\tau) \tau)$, where $r(\tau)$ is the riskless rate of return. In the absence of arbitrage opportunities, it is expected that:

$$
G(\tau)+F \mathrm{e}^{-y \tau}=F \mathrm{e}^{-r \tau}
$$

from which the implied risk premium is derived as:

$$
\Pi=y-r=-\frac{1}{\tau} \log \left(\left[1-\frac{G(\tau)}{F \mathrm{e}^{-r \tau}}\right]\right)
$$

Equation (6) gives an expression for the implied risk premium.

Equation (13) indicates that the risk premium embedded in an infrastructure-indexed bond contract is a function of the ratio of the cost of the infrastructure-indexed bond guarantee and the present value of the promised payment.

\section{Factors influencing the risk premium}

This section, we examine factors that influence the risk premium.

Proposition 1: The risk premium is negatively correlated with the value of the project.

Proof:

${ }^{4}$ See [2] for the proof of this formula. 
Differentiate Equation (13) with respect to $Q$ :

$$
\frac{\partial \Pi}{\partial Q}=-\frac{1}{\tau}\left(\frac{\mathrm{e}^{-\delta \tau}}{F \mathrm{e}^{-r \tau}-G(\tau)}\right) N\left(d_{2}\right) \leq 0
$$

Since $N\left(d_{2}\right) \geq 0$ and $G(\tau)<F \mathrm{e}^{-r \tau}$.

Remarks. An explanation for this result is that an appreciation in the value of the project leads to a lesser chance of the borrower defaulting on the promised payment of the infrastructure indexed bond. The risk premium falls, reflecting the reduced risk of default.

Proposition 2: The risk premium rises as the value of the project becomes more volatile.

Proof:

Differentiate Equation (13) with respect to $\sigma_{q}$ :

$$
\frac{\partial \Pi}{\partial \sigma_{q}}=\frac{1}{\sqrt{\tau}}\left(\frac{Q \mathrm{e}^{-\delta \tau}}{F \mathrm{e}^{-r \tau}-G(\tau)}\right) N^{\prime}\left(d_{2}\right) \geq 090^{\circ}
$$

Since $N^{\prime}\left(d_{2}\right) \geq 0$ and $G(\tau)<F \mathrm{e}^{-r \tau}$.

Remarks. An increase in the volatility of the value of the project increases the option-value component of the infrastructure-indexed bond. Consequently, the risk of default by the borrower rises, resulting in the rise in the risk premium.

Proposition 3: The impact of monetary policy on the risk premium is indeterminate.

Proof:

Differentiate Equation (13) with respect to $r$.

$$
\frac{\partial \Pi}{\partial r}=\frac{1}{\tau}\left(\frac{F \mathrm{e}^{-r \tau}}{F \mathrm{e}^{-r \tau}-G(\tau)}\right)\left(\frac{G(\tau)}{F \mathrm{e}^{-r \tau}}-N\left(d_{1}\right)\right)
$$

Remarks: The results indicate that the impact of monetary policy on the risk premium is indeterminate. A common view held by market analysts is that an expansionary monetary policy will help reduce risky spreads. Our result, however, indicates that the impact of monetary policy on the risky spread cannot be ascertained.

\section{Conclusions}

The paper calls for the creation of an African Investment Guarantee Agency (AIGA) to support and strengthen the financing of development projects, including infrastructure projects. The paper proposes that AIGA's function could be similar to the World Bank's MIGA but would cater to only investments in Africa, particularly in the area of infrastructure. The main objective of AIGA would be to provide noncommercial investment guarantees to African and non-African investors, private or public who are desirous of investing in Africa but do not have the appetite for the above non-commercial risks.

Using option-pricing techniques, the paper derives the cost of AIGA's guarantees and the associated implied risk premium. The results of the paper indi- 
cate that the risk premium embedded in a infrastructure-indexed bond contract is seen as a function of the ratio of the cost of the infrastructure-indexed bond guarantee and the present value of the promised payment.

The deficiency of the study is the lack of empirical evidence to demonstrate the operability of the model. Future studies could empirically test the model in a number of African countries. Nevertheless, the model provides an enormous potential for the private sector to support the financing of Africa's infrastructure.

\section{Acknowledgements}

The author would like to acknowledge the useful comments of colleagues at the Economic Commission for Africa. The author also thanks Dr. KwabenaDuffour who turned him into an Economist and continues to challenge and inspire him to be great. This paper is dedicated to the late mother of the author, Nana AfuaFofieOwiredua I (Mercy AmaAkuffo-Newman). However, any errors or omissions must be attributed to the author. Of course, the views expressed in this paper are those of the author and should not be attributed to the United Nations.

\section{Conflicts of Interest}

The author declares no conflicts of interest regarding the publication of this paper.

\section{References}

[1] World Bank (2010) Africa Infrastructure Country Diagnostic Washington DC, United States.

[2] Merton, R. (1977) An Analytical Derivation of the Cost of Deposit Insurance and loan Guarantees: An Application of Modern Option Pricing Theory. Journal of Banking and Finance, 1, 3-11. https://doi.org/10.1016/0378-4266(77)90015-2

[3] Atta-Mensah, J. (2015) The Valuation of Infrastructure Index Bonds. Journal of Mathematical Finance, 5, 328-336. https://doi.org/10.4236/jmf.2015.54028 